\title{
Increased expression of non-sulfated chondroitin correlates with adverse clinicopathological parameters in prostate cancer
}

Yvonne Hui-Fang Teng ${ }^{1}$, Puay-Hoon Tan ${ }^{1,2,3}$, Sing-Joo Chia ${ }^{4}$, Nor Azhari Bin Mohd Zam Weber Kam-On Lau ${ }^{5}$, Christopher Wai-Sam Cheng ${ }^{5}$, Boon-Huat Bay ${ }^{1}$ and George Wai-Cheong Yip ${ }^{1}$

${ }^{1}$ Department of Anatomy, Yong Loo Lin School of Medicine, National University of Singapore, Singapore; ${ }^{2}$ Department of Pathology, Singapore General Hospital, Singapore; ${ }^{3}$ Department of Pathology, Yong Loo Lin School of Medicine, National University of Singapore, Singapore; ${ }^{4}$ Department of Urology, Tan Tock Seng Hospital, Singapore and ${ }^{5}$ Department of Urology, Singapore General Hospital, Singapore

Chondroitin sulfate is a structurally diverse glycosaminoglycan, which contains a variable degree of sulfation that helps to determine its biological function. It is involved in the regulation of cellular activity and has been implicated in carcinogenesis. To determine if the non-sulfated chondroitin backbone has a functional role in prostate cancer, we analyzed its expression by immunohistochemistry using the 1B5 monoclonal antibody and a set of tissue microarrays constructed with 227 prostate specimen cores from 81 cases of benign prostate tissue and 77 cases of prostate cancer, of which 69 of these cases are matched. Non-sulfated chondroitin was found in the secretory epithelial cells and stromal regions of both prostatic adenocarcinoma and benign prostatic tissues, as well as in the basal cells of benign glands. A higher percentage of cancerous cells were stained positively for non-sulfated chondroitin as compared with benign secretory cells of the same patient. Cancerous cells stained more intensely for non-sulfated chondroitin. This increase in percentage of cells stained and increase in staining intensity were associated with higher pathological $\mathrm{T}$ stage and extraprostatic extension. Non-sulfated chondroitin expression (either staining intensity or percentage of cells stained) in adenocarcinoma and its peritumoral stroma correlated significantly with several clinicopathological parameters of unfavorable outcome, including higher pathological T stage and Gleason score, presence of tumor in both prostatic lobes, extraprostatic extension, seminal vesicle involvement and preoperative prostate-specific antigen levels. These data suggest that non-sulfated chondroitin is a potentially useful biomarker for prostate cancer, and may be involved in regulating prostate cancer behavior.

Modern Pathology (2008) 21, 893-901; doi:10.1038/modpathol.2008.70; published online 16 May 2008

Keywords: chondroitin; immunohistochemistry; prognosis; prostate cancer; tissue microarray

Carcinoma of the prostate is the most frequently diagnosed cancer among American men, and is second only to lung cancer in malignancy-related deaths. ${ }^{1}$ Indeed, men have a one in six lifetime risk of developing prostate cancer. Although comparatively less common in Asian populations, ${ }^{2}$ prostate

Correspondence: Dr P-H Tan, Department of Pathology, Singapore General Hospital, Outram Road, Singapore 169608, Singapore.

E-mail: tan.puay.hoon@sgh.com.sg or

Dr GW-C Yip, MBBS, PhD, Department of Anatomy, Yong Loo Lin School of Medicine, National University of Singapore, 4 Medical Drive, Block MD 10, Singapore 117597, Singapore.

E-mail: georgeyip@nus.edu.sg

Received 30 November 2007; revised 10 March 2008; accepted 19 March 2008; published online 16 May 2008 cancer has seen a rise of $118 \%$ from 6.6 to 14.4 per 100000 person-years among Chinese men in Singapore, ${ }^{3}$ where it is now the fifth commonest malignancy among all Singapore men. ${ }^{4}$ The natural history of prostate carcinoma is complex and not fully understood. The disease can be asymptomatic in some patients but present in a more aggressive form in others. This poses a challenge for urologists, as decisions must be made to either employ 'watchful waiting' or intervene therapeutically. It is thus important to identify molecular biomarkers that will be helpful in differentiating between quiescent cancers and aggressive ones. Several recent studies have demonstrated the use of Pin $1,{ }^{5}$ Akt- 1,2 , and $3^{6}$ and cyclin $\mathrm{D}^{7}$ as predictive factors of clinical 
outcome in prostate cancer. In this study, we aimed to determine if non-sulfated chondroitin, a glycosaminoglycan molecule, could potentially be used as a prognostic marker by analyzing its expression for correlations with clinicopathological parameters of prostate cancer.

Glycosaminoglycans are long, unbranched molecules composed of repeating disaccharide subunits of an amino sugar alternating with a uronic acid. ${ }^{8}$ The chondroitin backbone consists of $\mathrm{N}$-acetylgalactosamine (GalNAc) and glucuronic acid (GlcA) residues, which are modified by the addition of sulfate groups at various positions, such as the 4- and 6-hydroxyl positions of GalNAc and the 2- and 3-hydroxyl positions of GlcA, to produce chondroitin sulfate. ${ }^{9}$ Chondroitin sulfate chains are attached to core proteins to form chondroitin sulfate proteoglycans. These have been found to regulate cancer cell behavior and affect disease outcome in a number of malignancies, including cancers of the lung, breast, ovary, mouth, pharynx and skin. ${ }^{10-15}$

Previous studies have shown that expression of versican, a chondroitin sulfate proteoglycan, is increased in prostate cancer and inhibits cancer cell adhesion to fibronectin in the stromal matrix. ${ }^{16,17}$ Furthermore, high performance liquid chromatography analysis of glycosaminoglycans extracted from prostate cancer samples revealed that chondroitin-6-sulfate and dermatan sulfate were the predominantly upregulated components. ${ }^{18}$ Indeed, elevated levels of sulfated chondroitin were reported to be associated with poorer disease outcome in early stage prostate cancer. ${ }^{19,20}$

The biological activities of chondroitin sulfate, as well as its ability to bind to and interact with different growth factors and signaling molecules, are dependent on the presence of distinct sulfation motifs. ${ }^{21-23}$ However, recent studies suggest that non-sulfated chondroitin is also biologically active and is essential for cell division. ${ }^{22,24}$ Thus, we aimed to determine the expression pattern of this molecule in prostate cancer by immunohistochemistry using 1B5, a monoclonal antibody with established specificity for non-sulfated chondroitin. ${ }^{25,26}$ We also evaluated the potential use of non-sulfated chondroitin as a prognostic marker in prostate cancer by comparing its expression against clinicopathological parameters.

\section{Materials and methods}

\section{Clinical Materials}

Archival prostate adenocarcinoma samples and paired benign prostatic tissue specimens from corresponding patients were obtained from the Department of Pathology, Singapore General Hospital. The samples were collected from 89 patients who underwent radical prostatectomy from 2001 to 2004. Targeted areas of the specimens were identified and used for tissue microarray construction using the Beecher arrayer as previously described. ${ }^{27}$ The numbers and sizes of prostatic tissue microarray cores used in this study is shown in Table 1. Clinicopathological data were collected for statistical analysis. Ethics approval was obtained from the Institutional Review Board, Singapore General Hospital.

\section{Immunohistochemistry}

The monoclonal antibody 1B5 that recognizes chondroitinase ABC-digested non-sulfated chondroitin stubs was purchased from Seikagaku (Tokyo, Japan). Tissue microarray sections were processed for immunohistochemical staining as described previously.$^{28}$ Briefly, after deparaffinization and rehydration, endogenous peroxidase activity was quenched with $3 \%$ aqueous hydrogen peroxide for $30 \mathrm{~min}$. After rinsing with Tris-buffered saline, the sections were treated with $0.025 \mathrm{units} / \mathrm{ml}$ chondroitinase ABC (Sigma-Aldrich) and incubated for $2 \mathrm{~h}$ at $37^{\circ} \mathrm{C}$. They were then blocked with goat serum for $1 \mathrm{~h}$ at room temperature, and incubated at $4{ }^{\circ} \mathrm{C}$ overnight with the 1B5 antibody (1:100 dilution). After washing, biotinylated secondary antibody was added and incubated for $1 \mathrm{~h}$ at room temperature, followed by visualization of the staining by the avidin-biotincomplex technique using diaminobenzidine as the substrate (ABC kit, Vector Laboratories). The sections were counterstained with hematoxylin. Control sections were processed using the same protocol, but the chondroitinase ABC incubation step was omitted.

Table 1 Distribution of prostate specimen core sizes used for study (excluding specimen cores that dropped off during immunohistochemical processing)

\begin{tabular}{lcccc}
\hline \multirow{2}{*}{ Tissue microarray core sizes } & \multicolumn{2}{c}{ Benign prostate specimen } & & \multicolumn{2}{c}{ Prostate adenocarcinoma specimen } \\
\cline { 2 - 5 } & No. of cores & No. of cases represented & No. of cores & No. of cases represented \\
\hline $0.6 \mathrm{~mm}$ & 28 & 13 & 23 & 11 \\
$1.0 \mathrm{~mm}$ & 74 & 46 & 58 & 44 \\
$2.0 \mathrm{~mm}$ & 22 & 22 & 103 & 77 \\
Total & 124 & 81 & 22 & 77 \\
\hline
\end{tabular}




\section{Immunohistochemical Evaluation}

Sections were assessed for expression of non-sulfated chondroitin in secretory and basal cells of benign prostatic tissue, in malignant cells of adenocarcinoma specimens, and in the stromal components of both groups. The intensity of staining was noted as absent (0), weak $(1+)$, moderate $(2+)$ or strong $(3+)$. The percentage of cells stained was also recorded. For a tissue section stained heterogeneously with different intensities, a weighted average of intensity was computed as such: $\sum$ (intensity ${ }_{1} \times$ percentage of cells stained with intensity $\left.y_{1}\right)+\left(\right.$ intensity $_{2} \times$ percentage of cells stained with intensity $\left.y_{2}\right) \div$ total percentage of cells stained. Sections from different cores of the same specimen were independently scored, and average values for weighted average staining intensity and percentage of cells stained calculated for each sample. Positive differences in the values of these measurements in prostate cancer sections compared against paired benign prostatic tissues from corresponding patients were taken as upregulated expression of non-sulfated chondroitin, while negative values denoted reduced expression.

\section{Statistical Analysis}

Statistical analysis was performed using SPSS for Windows Version 12.0. Wilcoxon signed rank test was used to compare the means between variables. Associations between the immunohistochemical staining data and clinicopathological parameters were determined using Fisher's exact test. A $P$-value of $<0.05$ was considered to be statistically significant.

\section{Results}

\section{Clinical and Demographic Data}

Eighty-nine prostate cancer samples and paired benign prostatic tissue specimens from constructed tissue microarrays were used for immunohistochemical evaluation. The age of the patients ranged from 45 to 74 years, with a mean of 62.4 years and a median of 62 years. The study cohort predominantly consisted of Chinese patients (73 cases), while the remaining cases included Malays (six cases) and other minor ethnic groups (10 cases). Owing to loss of tissue sections during deeper cuts for immunohistochemical processing, expression of non-sulfated chondroitin was examined in a total of 227 prostate specimen cores from 81 cases of benign tissue and 77 cases of cancer as detailed in Table 1. Consequently, only 69 matched benign prostatic and adenocarcinoma cases were available to compare differences in means in immunohistochemical staining. Clinicopathological features of the 77 cancer samples are shown in Table 2.
Table 2 Clinicopathological features of 77 prostate cancer samples

\begin{tabular}{|c|c|}
\hline $\begin{array}{l}\text { Clinicopathological } \\
\text { parameter }\end{array}$ & $\begin{array}{l}\text { Frequency } \\
\text { distribution }\end{array}$ \\
\hline \multicolumn{2}{|l|}{ Age (years) } \\
\hline Median & 62 \\
\hline Minimum & 45 \\
\hline Maximum & 74 \\
\hline \multicolumn{2}{|l|}{ Pathological T staging } \\
\hline T2a & 4 \\
\hline $\mathrm{T} 2 \mathrm{~b}$ & 5 \\
\hline $\mathrm{T} 2 \mathrm{c}$ & 31 \\
\hline ТЗа & 25 \\
\hline T3b & 8 \\
\hline At least $\mathrm{T} 2 \mathrm{c}^{\mathrm{a}}$ & 3 \\
\hline Not available & 1 \\
\hline \multicolumn{2}{|l|}{ Gleason sum } \\
\hline Gleason sum 5 & 5 \\
\hline Gleason sum 6 & 27 \\
\hline Gleason sum 7 & 41 \\
\hline Gleason sum 8 & 2 \\
\hline Gleason sum 9 & 2 \\
\hline \multicolumn{2}{|c|}{ Maximum tumor dimension } \\
\hline$<2.5 \mathrm{~cm}$ & 39 \\
\hline$\geq 2.5 \mathrm{~cm}$ & 37 \\
\hline Not available & 1 \\
\hline \multicolumn{2}{|l|}{ Tumor volume } \\
\hline$<4.0 \mathrm{~cm}^{3}$ & 31 \\
\hline$\geq 4.0 \mathrm{~cm}^{3}$ & 29 \\
\hline Not available & 17 \\
\hline \multicolumn{2}{|l|}{ Extraprostatic extension } \\
\hline Yes & 33 \\
\hline No & 40 \\
\hline Cannot be assessed ${ }^{\mathrm{b}}$ & 3 \\
\hline Not available & 1 \\
\hline \multicolumn{2}{|l|}{ Lymphovascular invasion } \\
\hline Present & 10 \\
\hline Absent & 63 \\
\hline Not available & 4 \\
\hline \multicolumn{2}{|c|}{ Obturator lymph node metastasis } \\
\hline Yes & 0 \\
\hline No & 45 \\
\hline Not sampled & 32 \\
\hline \multicolumn{2}{|c|}{ Seminal vesicle involvement } \\
\hline Yes & 7 \\
\hline No & 69 \\
\hline Not available & 1 \\
\hline \multicolumn{2}{|l|}{ Perineural invasion } \\
\hline Seen & 62 \\
\hline Not seen & 15 \\
\hline
\end{tabular}

Resection margin involvement (other than at apex and bladder base/proximal margin)

Not involved

41

Not available

Apex (distal) margin involvement

Involved

34

Not involved

Not available 
Table 2 Continued

\begin{tabular}{lc}
\hline $\begin{array}{l}\text { Clinicopathological } \\
\text { parameter }\end{array}$ & $\begin{array}{l}\text { Frequency } \\
\text { distribution }\end{array}$ \\
\hline $\begin{array}{l}\text { Bladder base (proximal) margin involvement } \\
\text { Involved }\end{array}$ & 9 \\
Not involved & 68 \\
Clinical staging & \\
T1c & 36 \\
T2a & 3 \\
T2b & 4 \\
T2c & 1 \\
Not available & 33 \\
Preoperative PSA & \\
<8 ng/ml & \\
>8 ng/ml & 22 \\
Not available & 20 \\
& 35 \\
Lobe occurrence & \\
Both lobes & \\
Single lobe & 64 \\
Not available & 11 \\
\hline
\end{tabular}

aPathological T staging is classified as 'at least T2c' due to inability to ascertain the capsular status of the tumor.

${ }^{\mathrm{b}}$ Capsular integrity cannot be ascertained, as the site of the positive surgical margin does not disclose the capsule of the gland.

${ }^{\mathrm{C}}$ One case of absence of apex margin involvement consists of high-grade prostatic intraepithelial neoplasia (HG-PIN) found at the apex margin.

\section{Immunohistochemical Staining}

Localization of non-sulfated chondroitin in benign prostatic and adenocarcinoma tissues

In benign prostatic tissue, non-sulfated chondroitin was expressed at moderate to high intensity in basal cells and in the periglandular stroma (Figure 1a). Weaker staining intensity was detected in the cytoplasm of secretory cells and in the stromal connective tissue away from the immediate periglandular zones. In prostate cancer, immunohistochemical staining for non-sulfated chondroitin was seen in the cytoplasm of malignant cells and in the surrounding stroma (Figure 1b). The expression data of non-sulfated chondroitin in 81 cases of benign prostatic tissues and 77 cases of prostate adenocarcinoma samples are shown in Table 3 .

Comparison of non-sulfated chondroitin expression in benign prostatic and adenocarcinoma tissues

As shown in Table 4, when we compared staining differences in the means of 69 cases of matched benign and prostate adenocarcinoma tissues, we found that cancer cells were more intensely stained compared against benign secretory cells $(P=0.030)$. Furthermore, an average of $40 \%$ of cancer cells were positively stained for non-sulfated chondroitin, in contrast to an average of $25 \%$ of secretory cells in the benign prostatic group $(P=0.013)$. However, we did not observe any significant changes in staining intensity or percentage of cells stained in the peritumoral stroma, as compared to the periglandular stroma.
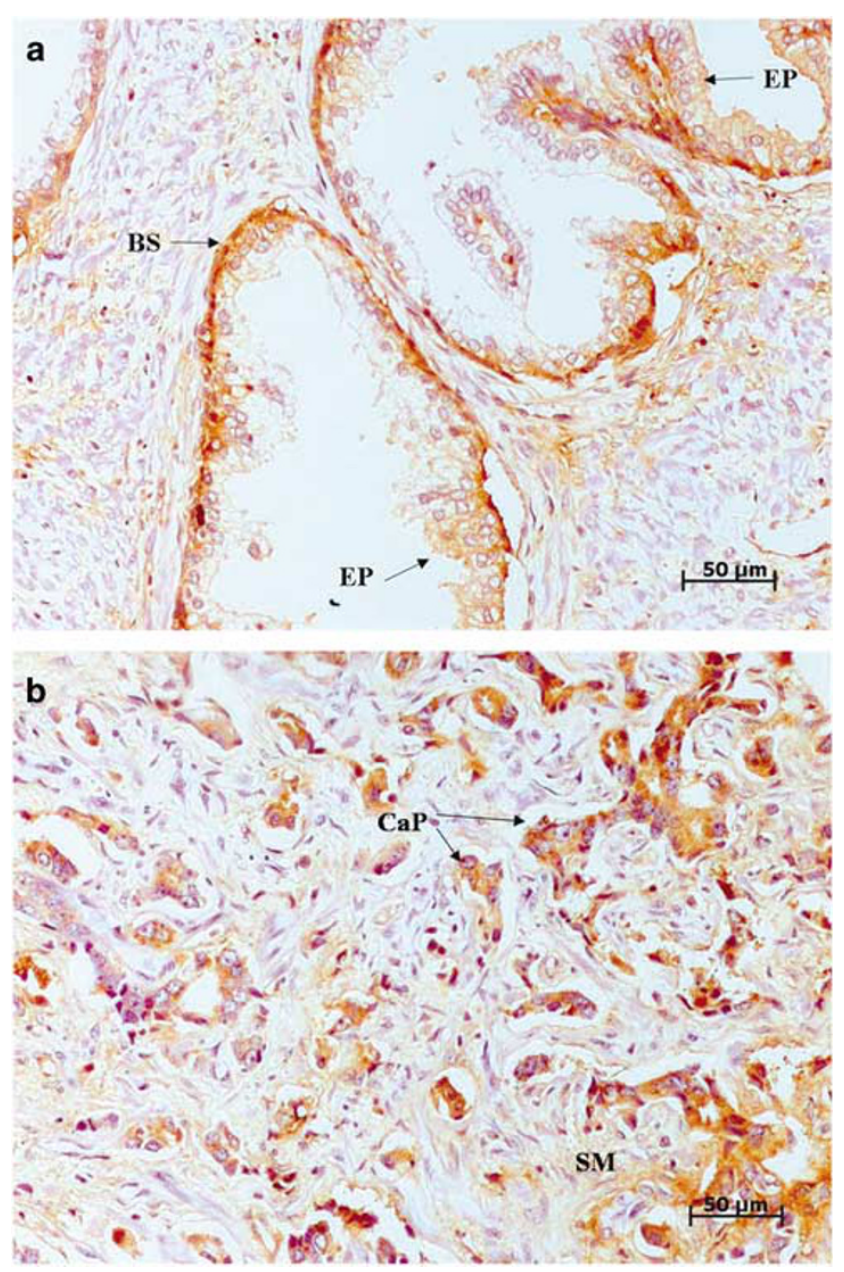

Figure 1 Expression of non-sulfated chondroitin in benign prostate tissues and prostate adenocarcinoma tissues. (a) The cytoplasm of the basal cells (BS) of the benign prostate tissue was stained strongly $(3+)$ for non-sulfated chondroitin while there was weaker staining $(1+)$ in the cytoplasm of benign secretory epithelial cells (EP). (b) The cytoplasm of prostate adenocarcinoma cells $(\mathrm{CaP})$ was stained intensely $(3+)$ for non-sulfated chondroitin while there was weak $(1+)$ to moderate $(2+)$ staining in the peritumoral stromal cells (SM).

\section{Association of Immunohistochemical Staining with Clinicopathological Parameters}

We examined the changes in staining intensity and percentage of cells stained for non-sulfated chondroitin in secretory epithelial cells of benign prostatic tissue and malignant cells of paired adenocarcinoma samples. When compared with clinicopathological parameters, increase in both staining intensity and percentage of cancer cells stained for non-sulfated chondroitin was found to be significantly associated with higher pathological $\mathrm{T}$ stage and presence of extraprostatic extension (Tables 5 and 6).

Analysis of absolute staining intensities for nonsulfated chondroitin in both prostate adenocarcinoma cells and peritumoral stroma showed significant associations with several clinicopathological parameters and known prognostic factors. Table 7 
Table 3 Expression of non-sulfated chondroitin in benign prostatic and adenocarcinoma tissues

\begin{tabular}{|c|c|c|c|c|c|c|c|}
\hline \multirow[t]{3}{*}{ Stained tissue component } & \multirow[t]{3}{*}{ Total number } & \multirow{3}{*}{$\begin{array}{c}\text { Number } \\
\text { unstained }\end{array}$} & \multicolumn{5}{|c|}{ Number stained } \\
\hline & & & \multicolumn{3}{|c|}{ Weighted average intensity (I) } & \multicolumn{2}{|c|}{ Percentage of cells } \\
\hline & & & $\leq 1$ & $1<I<2$ & $\geq 2$ & $\leq 50$ & $>50$ \\
\hline \multicolumn{8}{|l|}{ Benign } \\
\hline Secretory epithelial cells & 81 & $29(35.8 \%)$ & $21(25.9 \%)$ & $9(11.1 \%)$ & $22(27.2 \%)$ & $37(45.7 \%)$ & $15(18.5 \%)$ \\
\hline Periglandular stromal cells & 81 & $30(37.0 \%)$ & $17(21.0 \%)$ & $13(16.0 \%)$ & $21(26.0 \%)$ & $34(42.0 \%)$ & $17(21.0 \%)$ \\
\hline \multicolumn{8}{|l|}{ Adenocarcinoma } \\
\hline Cancerous cells & 77 & $17(22.0 \%)$ & $18(23.4 \%)$ & $15(19.5 \%)$ & $27(35.1 \%)$ & $33(42.9 \%)$ & $27(35.1 \%)$ \\
\hline Peritumoral stromal cells ${ }^{\mathrm{a}}$ & 76 & $20(26.3 \%)$ & $29(38.2 \%)$ & $11(14.4 \%)$ & $16(21.1 \%)$ & $36(47.4 \%)$ & $20(26.3 \%)$ \\
\hline
\end{tabular}

${ }^{\mathrm{a} O n e}$ adenocarcinoma section has too few stromal cells for analysis.

Table 4 Comparison of weighted average intensity and percentage of cells stained for non-sulfated chondroitin between 69 matched samples of benign/adenocarcinoma prostate sections

\begin{tabular}{|c|c|c|c|c|c|c|}
\hline & \multicolumn{3}{|c|}{ Weighted average intensity } & \multicolumn{3}{|c|}{ Percentage of cells stained (\%) } \\
\hline & Mean (s.e.m.) & Median & $\mathrm{P}$-value & Mean (s.e.m.) & Median & $\mathrm{P}$-value \\
\hline \multicolumn{7}{|l|}{ Epithelial/cancer cells } \\
\hline Benign secretory epithelial cells & $0.96(0.11)$ & 1.0 & $0.030^{\mathrm{a}}$ & $24.7(3.7)$ & 10.0 & $0.013^{\mathrm{a}}$ \\
\hline Adenocarcinoma cells & $1.29(0.11)$ & 1.2 & & $39.8(4.3)$ & 40.0 & \\
\hline \multicolumn{7}{|l|}{ Stromal region ${ }^{\mathrm{b}}$} \\
\hline Periglandular stromal cells & $1.03(0.12)$ & 1.0 & 0.516 & $28.3(4.4)$ & 10.0 & 0.109 \\
\hline Peritumoral stromal cells & $1.09(0.10)$ & 1.0 & & $35.6(4.4)$ & 20.0 & \\
\hline
\end{tabular}

s.e.m., standard error of the mean.

${ }^{\mathrm{a}}$ Statistically significant result.

$\mathrm{b}_{1}$ adenocarcinoma section has too few stromal cells for analysis. Thus, there are only a total of 68 matched benign/adenocarcinoma prostate stromal sections available for analysis.

Table 5 Association between changes in weighted average intensity of epithelial/cancerous cells in 69 paired benign and adenocarcinoma samples and clinicopathological parameters

\begin{tabular}{|c|c|c|c|c|}
\hline \multirow[t]{2}{*}{ Clinicopathological parameter } & \multirow[t]{2}{*}{ Total $^{\mathrm{a}}$} & \multicolumn{2}{|c|}{ Change in weighted average intensity of paired benign/cancer samples } & \multirow[t]{2}{*}{ P-value } \\
\hline & & No change/decrease & Increase & \\
\hline \multicolumn{5}{|l|}{ Pathological T staging } \\
\hline T2a to $\mathrm{T} 2 \mathrm{c}$ & 39 & $22(56.4 \%)$ & $17(43.6 \%)$ & $0.045^{\mathrm{b}}$ \\
\hline T3a to T3b & 27 & $8(29.6 \%)$ & $19(70.4 \%)$ & \\
\hline Total & $66^{\mathrm{c}}$ & & & \\
\hline \multicolumn{5}{|l|}{ Extraprostatic extension } \\
\hline Yes & 27 & $8(29.6 \%)$ & $19(70.4 \%)$ & $0.047^{\mathrm{b}}$ \\
\hline No & 38 & $21(55.3 \%)$ & $17(44.7 \%)$ & \\
\hline Total & $65^{\mathrm{d}}$ & & & \\
\hline
\end{tabular}

${ }^{\mathrm{a}} \mathrm{A}$ total of 69 matched pairs of benign prostatic and adenocarcinoma samples were available for analysis.

${ }^{\mathrm{b}}$ Statistically significant result.

${ }^{\mathrm{C}}$ Two cases classified as 'at least T2c' were excluded from analysis and there was unavailable information for one case.

${ }^{d}$ Extraprostatic extension for three cases cannot be ascertained and there was unavailable information for one case.

shows that pathological $\mathrm{T}$ stage, presence of extraprostatic extension, involvement of seminal vesicles, and pre-operative PSA levels were all correlated with strong expression of non-sulfated chondroitin in the peritumoral stroma. A strong expression of chondroitin in adenocarcinoma cells was also associated with involvement of both prostatic lobes. 
Table 6 Association between changes in percentage of epithelial/cancerous cells stained in 69 paired benign and adenocarcinoma samples and clinicopathological parameters

\begin{tabular}{lccc}
\hline Clinicopathological parameter & Total $^{\mathrm{a}}$ & Change in percentage of cells stained of paired benign/cancer samples & Increase \\
\cline { 3 - 4 } & & No change/decrease & \\
\hline Pathological T staging & & & $16(41.0 \%)$ \\
T2a to T2c & 39 & $7(25.9 \%)$ & $20(74.1 \%)$ \\
T3a to T3b & 27 & & $0.012^{\mathrm{b}}$ \\
Total & $66^{\mathrm{c}}$ & $7(25.9 \%)$ & $20(74.1 \%)$ \\
Extraprostatic extension & & $23(60.5 \%)$ & $15(39.5 \%)$ \\
Yes & 27 & & $0.011^{\mathrm{b}}$ \\
No & 38 & $65^{\mathrm{d}}$ &
\end{tabular}

${ }^{\mathrm{a}}$ A total of 69 matched pairs of benign prostatic and adenocarcinoma samples were available for analysis.

${ }^{\mathrm{b}}$ Statistically significant result.

${ }^{\mathrm{c}}$ Two cases classified as 'at least T2c' were excluded from analysis and there was unavailable information for one case.

${ }^{d}$ Extraprostatic extension for three cases cannot be ascertained and there was unavailable information for one case.

Table 7 Association between weighted average staining intensity of non-sulfated chondroitin in 77 prostate cancer samples and clinicopathological parameters

\begin{tabular}{|c|c|c|c|c|c|}
\hline Stained tissue component & $\begin{array}{l}\text { Clinicopathological } \\
\text { parameter }\end{array}$ & Total & $\begin{array}{l}\text { Weighted average } \\
\text { intensity }<2\end{array}$ & $\begin{array}{l}\text { Weighted average } \\
\text { intensity } \geq 2\end{array}$ & $\mathrm{P}$-value \\
\hline Adenocarcinoma cells & $\begin{array}{l}\text { Lobe occurrence } \\
\text { Single lobe } \\
\text { Both lobes } \\
\text { Total }\end{array}$ & $\begin{array}{r}11 \\
64 \\
75^{\mathrm{b}}\end{array}$ & $\begin{array}{l}11(100.0 \%) \\
38(59.4 \%)\end{array}$ & $\begin{array}{c}0(0.0 \%) \\
26(40.6 \%)\end{array}$ & $0.013^{\mathrm{a}}$ \\
\hline Peritumoral stroma ${ }^{\mathrm{c}}$ & $\begin{array}{l}\text { Pathological T staging } \\
\text { T2a to T2c } \\
\text { T3a to T3b } \\
\text { Total }\end{array}$ & $\begin{array}{r}39 \\
33 \\
72^{\mathrm{d}}\end{array}$ & $\begin{array}{l}34(87.2 \%) \\
22(66.7 \%)\end{array}$ & $\begin{array}{c}5(12.8 \%) \\
11(33.3 \%)\end{array}$ & $0.049^{\mathrm{a}}$ \\
\hline & $\begin{array}{l}\text { Extraprostatic extension } \\
\text { Yes } \\
\text { No } \\
\text { Total }\end{array}$ & $\begin{array}{r}33 \\
39 \\
72^{\mathrm{e}}\end{array}$ & $\begin{array}{l}22(66.7 \%) \\
34(87.2 \%)\end{array}$ & $\begin{array}{r}11(33.3 \%) \\
5(12.8 \%)\end{array}$ & $0.049^{\mathrm{a}}$ \\
\hline & $\begin{array}{l}\text { Seminal vesicle involvement } \\
\text { Involved } \\
\text { Not involved } \\
\text { Total }\end{array}$ & $\begin{array}{r}7 \\
68 \\
75^{\mathrm{f}}\end{array}$ & $\begin{array}{r}3(42.9 \%) \\
56(82.4 \%)\end{array}$ & $\begin{array}{r}4(57.1 \%) \\
12(17.6 \%)\end{array}$ & $0.034^{\mathrm{a}}$ \\
\hline & $\begin{array}{l}\text { Pre-op PSA } \\
\quad \leq 8 \mathrm{ng} / \mathrm{ml} \\
\quad>8 \mathrm{ng} / \mathrm{ml} \\
\text { Total }\end{array}$ & $\begin{array}{r}21 \\
20 \\
41^{g}\end{array}$ & $\begin{array}{l}21(100.0 \%) \\
15(75.0 \%)\end{array}$ & $\begin{array}{l}0(0.0 \%) \\
5(25.0 \%)\end{array}$ & $0.021^{\mathrm{a}}$ \\
\hline
\end{tabular}

${ }^{\mathrm{a}}$ Statistically significant result.

${ }^{\mathrm{b}}$ There was unavailable information for two cases.

${ }^{\mathrm{C}}$ One adenocarcinoma section has too few stromal cells for analysis. Thus, there was a total of 76 prostate peritumoral stromal sections available for analysis.

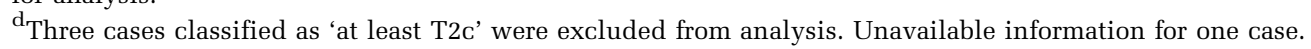

extraprostatic extension could not be assessed in three cases. Unavailable information for one case.

${ }^{\mathrm{f}}$ Unavailable information for one case.

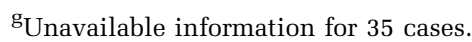

Examination of the percentage of tumor cells and peritumoral stromal cells stained positively for non-sulfated chondroitin revealed correlations with pathological T stage, Gleason scores and extraprostatic extension (Table 8).
No significant correlations were found when the expression patterns of non-sulfated chondroitin were analyzed with the other clinicopathological parameters listed in Table $2(P>0.05)$, namely clinical stage, tumor size and volume, resection 
Table 8 Association between percentage of cells positively stained for non-sulfated chondroitin in 77 prostate cancer samples and clinicopathological parameters

\begin{tabular}{|c|c|c|c|c|c|}
\hline Stained tissue component & $\begin{array}{l}\text { Clinicopathological } \\
\text { parameter }\end{array}$ & Total & $\begin{array}{l}\text { Percentage of positively } \\
\text { stained cells } \leq 50 \%\end{array}$ & $\begin{array}{l}\text { Percentage of positively } \\
\text { stained cells }>50 \%\end{array}$ & $\mathrm{P}$-value \\
\hline \multirow[t]{8}{*}{ Adenocarcinoma cells } & Pathological T stage & & & & \\
\hline & T2a to T2c & 40 & $30(75.0 \%)$ & $10(25.0 \%)$ & 0.050 \\
\hline & $\mathrm{T} 3 \mathrm{a}$ to $\mathrm{T} 3 \mathrm{~b}$ & 33 & $17(51.5 \%)$ & $16(48.5 \%)$ & \\
\hline & Total & $73^{\mathrm{a}}$ & & & \\
\hline & Extraprostatic extension & & & & \\
\hline & Yes & 33 & $17(51.5 \%)$ & $16(48.5 \%)$ & 0.050 \\
\hline & No & 40 & $30(75.0 \%)$ & $10(25.0 \%)$ & \\
\hline & Total & $73^{\mathrm{b}}$ & & & \\
\hline \multirow[t]{4}{*}{ Peritumoral stroma $^{\mathrm{c}}$} & Gleason sum & & & & \\
\hline & $5-6$ & 31 & $27(87.1 \%)$ & $4(12.9 \%)$ & $0.035^{\mathrm{d}}$ \\
\hline & 7-9 & 45 & $29(64.4 \%)$ & $16(35.6 \%)$ & \\
\hline & Total & 76 & & & \\
\hline
\end{tabular}

'Three cases classified as 'at least T2c' were excluded from analysis. Unavailable information for one case.

${ }^{b}$ Extraprostatic extension could not be assessed in three cases. Unavailable information for one case.

${ }^{\mathrm{C}}$ One adenocarcinoma section has too few stromal cells for analysis. Thus, there are only a total of 76 prostate peritumoral stromal sections available for analysis.

${ }^{\mathrm{d}}$ Statistically significant result.

margin including distal and proximal margin involvement, lymphovascular invasion and perineural invasion. We were unable to correlate with obturator lymph node involvement as none of our patients demonstrated metastases to nodes (Table 2).

\section{Discussion}

In this study, we have examined the expression patterns of non-sulfated chondroitin in benign prostatic tissue and paired prostate cancer samples from corresponding patients. Non-sulfated chondroitin was overexpressed in adenocarcinoma cells compared against corresponding benign secretory cells, and this upregulation was associated with higher pathological $\mathrm{T}$ stage and extraprostatic extension. Strong expression of non-sulfated chondroitin in the cancer cells as well as a large number of positively stained cancer cells, correlated with occurrence of cancer in both prostate lobes, pathological $\mathrm{T}$ stage and extraprostatic extension. Similarly, a strong expression of non-sulfated chondroitin in cancer stroma and a large number of positively stained peritumoral stromal cells, correlated with Gleason scores, pathological T stage, extraprostatic extension, seminal vesicle involvement and pre-operative PSA levels. All these pathologic parameters augur a worse prognosis for patients, and underscore the association of nonsulfated chondroitin expression with conventional adverse predictors.

Studies on chondroitin sulfate proteoglycans have shown that they play important roles in cancer biology, and may be useful prognostic factors in breast, lung, ovarian and skin cancers. ${ }^{10,13,14,29-31}$ Several immunohistochemical studies focusing on the sulfated chondroitin chain have shown that high stromal levels of this molecule is associated with a poor outcome in patients with early-stage prostate cancer. ${ }^{19,20}$ Furthermore, increased expression of the core proteins of versican in the peritumoral stroma, and PTEN (two chondroitin sulfate proteoglycans) has also been reported to be predictive of poor prognosis in early-stage prostate cancer patients. ${ }^{16,32}$

To date, the role of the non-sulfated chondroitin backbone in prostate cancer has not been examined. Although it is well established that sulfate groups on chondroitin sulfate, heparan sulfate and other sulfated glycosaminoglycans are important determinants of the binding and biological actions of these molecules, some studies suggest that non-sulfated chondroitin may be biologically active as well. This has been highlighted by several recent reports on inhibiting biosynthesis of non-sulfated chondroitin by RNA interference, which demonstrated that the molecule is essential for cell proliferation, cytokinesis and migration, and may underlie the mechanistic processes leading to the association of nonsulfated chondroitin with adverse pathologic parameters as observed in our study. ${ }^{22,24,33}$

Chondroitin may regulate prostate cancer cell behavior and influence patient prognosis through several mechanisms. Platelet-derived growth factors (PDGFs) are involved in regulating proliferation of cancer cells and stimulating tumor angiogenesis, and chondroitin sulfate has been shown to enhance PDGF action by enhancing signaling of the tyrosine kinase receptors. ${ }^{34}$ Indeed, PDGF and its receptor have been reported to be upregulated in prostate adenocarcinoma, and expression of PDGF receptor has been shown to mark prostate cancer cells with the greatest disposition for bony metastasis..$^{35,36}$ 
Stromal cell-derived factor-1 (SDF-1) is a chemoattractant for prostate carcinoma cells. ${ }^{37}$ Chondroitin sulfate has been shown to be required for cellular binding of SDF-1. ${ }^{38}$ In prostate carcinoma, treatment of cancer cells with SDF-1 upregulated expression of $\alpha_{\mathrm{v}} \beta_{3}$ integrin receptors, resulting in increased cell adhesion and invasion. ${ }^{39}$ Furthermore, SDF-1 has been shown to be critical for spread of prostate cancer, and a positive correlation has been reported between SDF-1 signaling and bony metastasis. ${ }^{40,41}$

Pleiotrophin, also known as heparin affin regulatory peptide or heparin-binding growth-associated molecule, is an important regulator of cancer growth and angiogenesis. ${ }^{42}$ Pleiotrophin expression has been reported in prostate cancer cells, but not in epithelial cells derived from normal or hyperplastic prostate. ${ }^{43}$ Overexpression of pleiotrophin resulted in anchorageindependent growth. The importance of this molecule on prostate cancer cell growth and migration was further confirmed using antisense inhibition of pleiotrophin expression. ${ }^{44}$ Recent studies have shown that pleiotrophin is able to bind to chondroitin sulfate in addition to heparan sulfate, and that chondroitin sulfate helps in the transfer of the growth factor to its receptor on the cell surface. ${ }^{45}$ Pleiotrophin has also been demonstrated to function downstream of fibroblast growth factor-2 (FGF2) in increasing prostate cancer cellular proliferation and migration. ${ }^{46}$ Inhibition of pleiotrophin expression in human prostate cancer LNCaP cells rendered them unable to respond to the FGF2 stimulus, resulting in an absence of increased cell proliferation and migration.

The prostate adenocarcinoma samples that were analyzed in this study were limited in their representation of the entire range of cancers especially for some of the clinicopathological parameters. For instance, no obturator lymph node metastases were observed in the patient cohort studied and therefore makes it unavailable for studying the association of this parameter with non-sulfated chondroitin staining. Besides, the small number of cases observed for positive lymphovascular invasion, presence of seminal vesicle involvement and proximal margin involvement contributes to the difficulty of making a strong association between these parameters and nonsulfated chondroitin staining. In addition, many of these prostate adenocarcinoma samples are of intermediate tumor grade (Gleason sum of 6 or 7) while there is a very small group of low-grade or highgrade tumors. In our study, we were unable to determine any associations of non-sulfated chondroitin staining with PSA relapse and survival due to the short period of patient follow-up. As such, future work will include collecting prostate adenocarcinoma samples that encompass a broader spectrum of prostate cancer disease, and a longer period of patient follow-up with data acquisition to further determine whether non-sulfated chondroitin will be a good indicator of prostate cancer progression.
Nevertheless, we have shown a significant increase in expression of non-sulfated chondroitin in prostate adenocarcinoma compared against paired benign prostatic tissue samples from corresponding patients, and that this is associated with several important clinicopathological parameters of poor prognosis. This suggests that non-sulfated chondroitin may be useful as a biomarker and predictive factor of patient outcome in prostate cancer, and may also serve as a potential therapeutic target to improve patient treatment and outcome.

\section{Acknowledgements}

We thank Ms Sii Lang Hiong and Ms Tan Yen for excellent technical assistance. The project was supported by grants from the National Medical Research Council, Singapore (GWY) and the Singapore Cancer Syndicate MS0004 (P-HT). YH-FT is the recipient of a graduate research scholarship from the National University of Singapore.

\section{References}

1 Jemal A, Siegel R, Ward E, et al. Cancer statistics, 2007. CA Cancer J Clin 2007;57:43-66.

2 Hsing AW, Tsao L, Devesa SS. International trends and patterns of prostate cancer incidence and mortality. Int J Cancer 2000;85:60-67.

3 Sim HG, Cheng CW. Changing demography of prostate cancer in Asia. Eur J Cancer 2005;41:834-845.

4 Seow A, Koh WP, Chia KS, et al. Trends in Cancer Incidence in Singapore 1968-2002. Singapore Cancer Registry: Singapore, 2004.

5 Ayala G, Wang D, Wulf G, et al. The prolyl isomerase Pin1 is a novel prognostic marker in human prostate cancer. Cancer Res 2003;63:6244-6251.

6 Le Page C, Koumakpayi IH, Alam-Fahmy M, et al. Expression and localisation of Akt-1, Akt-2 and Akt-3 correlate with clinical outcome of prostate cancer patients. Br J Cancer 2006;94:1906-1912.

7 Drobnjak M, Osman I, Scher HI, et al. Overexpression of cyclin D1 is associated with metastatic prostate cancer to bone. Clin Cancer Res 2000;6:1891-1895.

8 Yip GW, Smollich M, Gotte M. Therapeutic value of glycosaminoglycans in cancer. Mol Cancer Ther 2006;5:2139-2148.

9 Silbert JE, Sugumaran G. Biosynthesis of chondroitin/ dermatan sulfate. IUBMB Life 2002;54:177-186.

10 Pirinen R, Leinonen T, Bohm J, et al. Versican in nonsmall cell lung cancer: relation to hyaluronan, clinicopathologic factors, and prognosis. Hum Pathol 2005;36:44-50.

11 Pukkila M, Kosunen A, Ropponen K, et al. High stromal versican expression predicts unfavourable outcome in oral squamous cell carcinoma. J Clin Pathol 2007;60:267-272.

12 Pukkila MJ, Kosunen AS, Virtaniemi JA, et al. Versican expression in pharyngeal squamous cell carcinoma: an immunohistochemical study. J Clin Pathol 2004;57: 735-739.

13 Suwiwat S, Ricciardelli C, Tammi R, et al. Expression of extracellular matrix components versican, chon- 
droitin sulfate, tenascin, and hyaluronan, and their association with disease outcome in node-negative breast cancer. Clin Cancer Res 2004;10:2491-2498.

14 Voutilainen K, Anttila M, Sillanpaa S, et al. Versican in epithelial ovarian cancer: relation to hyaluronan, clinicopathologic factors and prognosis. Int J Cancer 2003;107:359-364.

15 Yang J, Price MA, Neudauer CL, et al. Melanoma chondroitin sulfate proteoglycan enhances FAK and ERK activation by distinct mechanisms. J Cell Biol 2004;165:881-891.

16 Ricciardelli C, Mayne K, Sykes PJ, et al. Elevated levels of versican but not decorin predict disease progression in early-stage prostate cancer. Clin Cancer Res 1998;4: 963-971.

17 Sakko AJ, Ricciardelli C, Mayne K, et al. Modulation of prostate cancer cell attachment to matrix by versican. Cancer Res 2003;63:4786-4791.

18 Iida S, Suzuki K, Matsuoka K, et al. Analysis of glycosaminoglycans in human prostate by high-performance liquid chromatography. Br J Urol 1997;79:763-769.

19 Ricciardelli C, Mayne K, Sykes PJ, et al. Elevated stromal chondroitin sulfate glycosaminoglycan predicts progression in early-stage prostate cancer. Clin Cancer Res 1997;3:983-992.

20 Ricciardelli C, Quinn DI, Raymond WA, et al. Elevated levels of peritumoral chondroitin sulfate are predictive of poor prognosis in patients treated by radical prostatectomy for early-stage prostate cancer. Cancer Res 1999;59:2324-2328.

21 Gama CI, Tully SE, Sotogaku N, et al. Sulfation patterns of glycosaminoglycans encode molecular recognition and activity. Nat Chem Biol 2006;2:467-473.

22 Sugahara K, Mikami T, Uyama T, et al. Recent advances in the structural biology of chondroitin sulfate and dermatan sulfate. Curr Opin Struct Biol 2003;13:612-620.

23 Zou XH, Foong WC, Cao T, et al. Chondroitin sulfate in palatal wound healing. J Dent Res 2004;83:880-885.

24 Mizuguchi S, Uyama T, Kitagawa H, et al. Chondroitin proteoglycans are involved in cell division of Caenorhabditis elegans. Nature 2003;423:443-448.

25 Couchman JR, Caterson B, Christner JE, et al. Mapping by monoclonal antibody detection of glycosaminoglycans in connective tissues. Nature 1984;307:650-652.

26 Fujita SC, Tada Y, Murakami F, et al. Glycosaminoglycanrelated epitopes surrounding different subsets of mammalian central neurons. Neurosci Res 1989;7:117-130.

27 Tan PH, Jayabaskar T, Yip GW, et al. p53 and c-kit (CD117) protein expression as prognostic indicators in breast phyllodes tumors: a tissue microarray study. Mod Pathol 2005;18:1527-1534.

28 Koo CY, Bay BH, Lui PC, et al. Immunohistochemical expression of heparan sulfate correlates with stromal cell proliferation in breast phyllodes tumors. Mod Pathol 2006;19:1344-1350.

29 Miquel-Serra L, Serra M, Hernandez D, et al. V3 versican isoform expression has a dual role in human melanoma tumor growth and metastasis. Lab Invest 2006;86:889-901.

30 Monzavi-Karbassi B, Stanley JS, Hennings L, et al. Chondroitin sulfate glycosaminoglycans as major P-selectin ligands on metastatic breast cancer cell lines. Int J Cancer 2007;120:1179-1191.

31 Ricciardelli C, Brooks JH, Suwiwat S, et al. Regulation of stromal versican expression by breast cancer cells and importance to relapse-free survival in patients with node-negative primary breast cancer. Clin Cancer Res 2002;8:1054-1060.

32 Glynne-Jones E, Harper ME, Seery LT, et al. TENB2, a proteoglycan identified in prostate cancer that is associated with disease progression and androgen independence. Int J Cancer 2001;94:178-184.

33 Izumikawa $\mathrm{T}$, Kitagawa $\mathrm{H}$, Mizuguchi $\mathrm{S}$, et al. Nematode chondroitin polymerizing factor showing cell-/organ-specific expression is indispensable for chondroitin synthesis and embryonic cell division. J Biol Chem 2004;279:53755-53761.

34 Fthenou E, Zafiropoulos A, Tsatsakis A, et al. Chondroitin sulfate A chains enhance platelet derived growth factor-mediated signalling in fibrosarcoma cells. Int J Biochem Cell Biol 2006;38:2141-2150.

35 Dolloff NG, Shulby SS, Nelson AV, et al. Bone-metastatic potential of human prostate cancer cells correlates with Akt/PKB activation by alpha platelet-derived growth factor receptor. Oncogene 2005;24:6848-6854.

36 Fudge K, Wang CY, Stearns ME. Immunohistochemistry analysis of platelet-derived growth factor A and B chains and platelet-derived growth factor alpha and beta receptor expression in benign prostatic hyperplasias and Gleason-graded human prostate adenocarcinomas. Mod Pathol 1994;7:549-554.

37 Cooper CR, Chay CH, Gendernalik JD, et al. Stromal factors involved in prostate carcinoma metastasis to bone. Cancer 2003;97:739-747.

38 Netelenbos T, van den BJ, Kessler FL, et al. Proteoglycans on bone marrow endothelial cells bind and present SDF-1 towards hematopoietic progenitor cells Leukemia 2003;17:175-184.

39 Sun YX, Fang M, Wang J, et al. Expression and activation of alpha(v)beta(3) integrins by SDF-1/ CXC12 increases the aggressiveness of prostate cancer cells. Prostate 2007;67:61-73.

40 Sun YX, Schneider A, Jung Y, et al. Skeletal localization and neutralization of the SDF-1(CXCL12)/CXCR4 axis blocks prostate cancer metastasis and growth in osseous sites in vivo. J Bone Miner Res 2005;20:318-329.

41 Taichman RS, Cooper C, Keller ET, et al. Use of the stromal cell-derived factor-1/CXCR4 pathway in prostate cancer metastasis to bone. Cancer Res 2002;62:1832-1837.

42 Papadimitriou E, Polykratis A, Hatziapostolou M, et al. Heparin affin regulatory peptide: a new target for tumor therapy? Curr Cancer Drug Targets 2004;4:471-482.

43 Vacherot F, Caruelle D, Chopin D, et al. Involvement of heparin affin regulatory peptide in human prostate cancer. Prostate 1999;38:126-136.

44 Hatziapostolou M, Delbe J, Katsoris P, et al. Heparin affin regulatory peptide is a key player in prostate cancer cell growth and angiogenicity. Prostate 2005;65 151-158.

45 Deepa SS, Yamada S, Zako M, et al. Chondroitin sulfate chains on syndecan-1 and syndecan-4 from normal murine mammary gland epithelial cells are structurally and functionally distinct and cooperate with heparan sulfate chains to bind growth factors. A novel function to control binding of midkine, pleiotrophin, and basic fibroblast growth factor. J Biol Chem 2004;279:37368-37376.

46 Hatziapostolou M, Polytarchou C, Katsoris P, et al. Heparin affin regulatory peptide/pleiotrophin mediates fibroblast growth factor 2 stimulatory effects on human prostate cancer cells. J Biol Chem 2006;281:32217-32226. 